\title{
Are we ready for genome editing in human embryos FOR CLINICAL PURPOSES?
}

\author{
Joyce C Harper and Gerald Schatten
}

Joyce C Harper, Professor of Reproductive Science, Institute for Women's Health, University College Londona

Gerald Schatten, Professor of Ob-Gyn-Repro Sci, Cell Biology and Bioengineering, University of Pittsburgh School of Medicine ${ }^{b}$

aInstitute for Women's Health, University College London, 86-96 Chenies Mews, London, WC1E 6HX, UK, 00447880 795791, joyce.harper@ucl.ac.uk (Corresponding author)

b204 Craft Avenue Pittsburgh, PA 15213

412/641-2403 [phone]

412/641-6342 [fax]

schattengp@upmc.edu gschatten@pdc.magee.edu

\begin{abstract}
Perhaps the two most significant pioneering biomedical discoveries with immediate clinical implications during the past forty years have been the advent of assisted reproductive technologies (ART) and the genetics revolution. ART, including in vitro fertilization (IVF), intracytoplasmic sperm injection and preimplantation genetic testing, has resulted in the birth of more than 8 million children, and the pioneer of IVF, Professor Bob Edwards, was awarded the 2010 Nobel Prize. The genetics revolution has resulted in our genomes being sequenced and many of the molecular mechanisms understood, and technologies for genomic editing have been developed. With the combination of nearly routine ART protocols for healthy conceptions together with almost errorfree, inexpensive and simple methods for genetic modification, the question "Are we ready for genome editing in human embryos FOR CLINICAL PURPOSES?" was debated at the 5th Congress on Controversies in Preconception, Preimplantation and Prenatal Genetic Diagnosis, in collaboration with the Ovarian Club Meeting, in November 2018 in Paris. The co-authors each presented scientific, medical and bioethical backgrounds, and the debate was chaired by Professor Alan Handyside. In this paper, we consider whether genome editing is safe and ethical. We conclude that we are currently not ready for genome editing to be used in human embryos for clinical purposes, and we call for a global debate to determine if and when this technology could be used in ART.
\end{abstract}

Keywords: assisted reproductive technologies (ART); genome editing; human reproduction; designer babies; bioethics; human Crispr-Cas 9 


\section{INTRODUCTION AND BACKGROUND}

It has been 40 years since the first success of in vitro fertilization with the birth of Louise Brown (Steptoe and Edwards, 1978) and almost 30 years since the first birth by preimplantation genetic testing (PGT; Handyside et al., 1990). The clinical success of both procedures was met with concern by the public, fears that subsided over the years as the benefits became established.

A new controversial procedure has arrived. Genome editing is advancing at a rapid pace since the use of the technique CRISPR-Cas 9 was first reported. And the potential of using this procedure to edit the genome of the preimplantation embryo has been the subject of much debate. In the USA, the Academy of Sciences produced a document, in February 2017, titled Human Genome Editing (National Academy of Sciences), which was followed by the Nuffield Council on Bioethics document, Genome Editing and Human Reproduction: Social and Ethical Issues, in July 2018 (Nuffield Council on Bioethics). Both reports called for robust research and ethical discussions before genome editing of human embryos is applied clinically.

At issue is the question of whether or not designer babies represents another forward step in the progression of medically warranted therapies that might eventually be acceptable to our society at large. The question is complicated by many factors, including the definition of 'designer baby' itself. Indeed, Professor Handyside, who moderated the 2018 debate, recently published an article entitled "Designer Babies' Almost Thirty Years On", referring to his pioneering discoveries in PGT (Handyside, 2018). The New York Times, on December 1, 2018, wrote an article with the headline 'Genetically Modified People Are Walking Among Us', noting that so-called 'three-parent' offspring were generated inadvertently by Jacques Cohen's team after cytoplasmic transfer (Brenner et al., 2000; Barratt et al, 2001), as well as deliberately by John Zhang's clinics, who largely followed the rules defined by the UK's Human Fertilisation and Embryology Authority (Zhang et al., 2007).

Clinical ART differs in many ways from other types of medicine (Schatten, 2002). Of perhaps greatest importance, ART has generational consequences. Methods such as intracytoplasmic sperm injection (ICSI) were tested and perfected in humans prior to animals, in part since the human oocyte appears more durable than that of the lab mouse (Schatten et al., 1998). Further, human embryo research in the US has been sponsored solely by the private sector and nearly exclusively by infertility clinics, outside of the competitive arena of fundamental science. Given its relatively brief clinical history and the absence of medical insurance companies participating in the evaluation of the effectiveness of these therapies especially in the US, this has made it difficult for practitioners and researchers to agree on criteria for its safety and success. Commercial market pressure on clinical practices to immediately occupy the most innovative forefront opened by research has resulted in arguably risky germ-line genetic modifications and genome editing claims. Reproduction, once governed largely 
by passion and instinct, now seems to need further governance.

In this article, we consider the safety and ethical issues surrounding human embryonic genome editing with the intent to generate babies with altered genomes.

\section{ART practices}

Over the 40 years since the birth of Louise Brown, assisted reproductive technology (ART) has advanced at a rapid pace. We can help men who have low sperm counts by using ICSI (Palermo et al., 1992) and those who are azoospermic by performing aspiration of sperm from the male reproductive tract (Flannigan et al., 2017), we can freeze eggs for medical and social reasons (Argyll et al., 2016), and we can make new types of families for single parents (Graham, 2017) and homosexual couples (Blake et al., 2017), and women in their 50s and 60s can give birth (Sauer, 2015).

PGT was initially performed for patients who were at risk of transmitting a genetic disease to their offspring (Handyside et al., 1990, Harper and Handyside, 1994, Harper, 1996). But in the mid-1990s, preimplantation genetic screening (PGS now PGT-A) was developed in the USA with the aim of improving the ART live birth rate (Harper, 2018). Our recent analysis of the UK and USA PGT data found that, in the UK, PGT only accounts for $1 \%$ of all ART cycles, but in the USA, it is applied to over $20 \%$ of cycles (Theobald et al., submitted).

PGT can be used to accurately diagnose the gender of preimplantation embryos. This is illegal in the European Union but is legal in other countries, including the USA (Ethics Committee of the American Society for Reproductive Medicine, $2015,2018)$; but there are no accurate figures on the use of gender selection globally. There are companies offering PGT to select for eye colour. And recently a report was published stating that a USA company aims soon to offer PGT for intelligence (Wilson, 2018).

The first human genome was sequenced in 2001 (Lander et al., 2001; Venter et al., 2001). James Watson had his genome sequenced in 2007 at the cost of around $\$ 1.5$ million, and it took several years. Within just 10 , years it was possible to have a human genome sequenced for under $\$ 1000$, and it takes just a few hours. The cost and efficiency of sequencing has decreased remarkably, though annotation of human genetic variation remains complex and incomplete at the current time. Soon we will be able to fully sequence preimplantation embryos. Fertile couples may consider it a genetic advantage to determine their healthiest embryos, or those with the characteristics they desire, using PGT and sequencing.

\section{Genome editing - is it safe?}

The Nobel Prize awarded to Drs. Mario R. Capecchi, Martin J. Evans and Oliver Smithies in 2007, was largely in recognition that the procedures for introducing 
specific gene modifications resulting in transgenic offspring (Nobel Prize, 2007) was by then straightforward, routine and an essential expertise taught to almost every biologist studying mammals (Nagy et al., 2003). Genome modification approaches generating offspring were extended from mice to domestic species as well as non-human primates (Chan et al., 2001).

Until breakthrough discoveries using the CRISPR-Cas9 gene editing procedures, the methods for genetic insertions, corrections and deletions were relatively primitive and error-prone. While invaluable for laboratory and other animals, these limitations discouraged any attempts in applying these tools to generating genetically altered humans.

CRISPR-Cas9 is much more accurate than prior methods of gene editing. The CRISPR/Cas9 system is like molecular scissors that can find and replace sequences of DNA (Zhang et al., 2014, Waddington et al., 2016). The heart of the gene editing system entails the CRISPR (Clustered Regularly Interspaced Short Palindromic Repeats) sequences forming a complex with Cas9 (CRISPRassociated 9) to establish the CRISPR/Cas9 system. The Cas9 nuclease cuts the DNA double strand at the position to be edited, and the programmable sequencespecific CRISPR acts as a guide to get the Cas9 to the specific sequence of DNA that is complementary to the CRISPR sequence. The cell's own DNA repair mechanisms lead to the desired insertions, deletions of substitutions at the target site.

The prowess of CRISPR/Cas9 and even better improvements in gene editing methods can be predicted to make safer, more efficient, easier and less expensive strategies for precisely modifying the genomes of every organism viruses, bacteria, fungi, plants and animals. Indeed, an improved version of the Cas9 nuclease, Cas 12 has just been reported (Strecker et al., 2019). These offer significant benefits in agriculture and medicine as well as for scientific discoveries.

These advances in molecular biology, including the sequencing of the human genome, combined with improvements in animal husbandry as well as stem cell techniques, bring us now to an era in which the reagents for genetic modifications are readily available, inexpensive and under variable, often inadequate, regulations. Ironically, greater oversight is exercised for motor vehicle drivers or SCUBA divers, than for genome modifiers. Given the swift pace of these discoveries and optimizations, the question before use is not whether genome editing will be useful in vitro for defining the causes of idiopathic infertility or better contraceptives or whether it might ever be shown to be safe and effective, but rather, Is it ready for clinical application resulting in babies resulting from genome editing now?

There is no doubt that genome editing using CRISPR/Cas 9 is an efficient and cheap procedure. But editing a human embryo has raised, at least, two 
challenges: mosaicism and off-target effects (Li et al., 2017). Mosaicism is where the edit does not appear in every cell of the embryo (Mehravar et al., 2019). Offtarget effects are ones in which other parts of the genome may be edited, with unknown consequences (Wilson et al., 2018). Before genome editing can be applied clinically, it is essential to ensure that both issues are resolved and that other potential adverse effects on the embryo are eliminated. Any children born following genome editing of embryos will need long-term follow up.

\section{Genome editing - is it ethical?}

Current research suggests that it may be many years before human embryonic genome editing is considered safe for clinical use. But on Monday, $26^{\text {th }}$

November, 2018, the scientific community were stunned to hear that $\mathrm{Dr} \mathrm{He}$ Jiankui in China had a birth from human embryos in which he claimed to have edited the genome. He Jiankui stated that he edited the DNA of seven embryos being used for fertility treatment, so far resulting in the birth of one set of twin girls. He said he used CRISPR to delete the embryos' CCR5 gene (C-C motif chemokine receptor 5), mutations in which are linked to resistance to HIV infection. The patients were HIV-positive men who had the infection under control and HIV-negative women. The risk of transmission of HIV for these couples would have been negligible, and there are well-established ways to prevent HIV transmission to the offspring of HIV-positive couples. It would be essential to see the preliminary work that $\mathrm{Dr}$ Jiankui has done to confirm that his technique has eliminated mosaicism and off-target effects, and it is surprising that he has not published this. While the outcome of the initial investigation in China is not yet known, China's official news agency, Xinhua, reported that Dr. He's '... behavior seriously violated ethics, scientific research integrity and relevant state regulations causing adverse effects at home and abroad' (Xinhua, 2019), and it seems there will be serious punishment for violations of the law, which appear to involve fabricated ethics approvals and improper informed consent (New York Times, 2019).

While Dr. He's claims cannot yet be verified and may not necessarily be overstatements, it is worthwhile to note that others have publicly stated alleged scientific breakthroughs, such as human embryo cloning, which were certainly false (Schatten et al., 2003). It will be worthwhile to examine facts as they appear in peer-reviewed publications and separately confirmed by independent laboratories. Equally important is the examination of motives, professional and personal, for physicians and other scientists, as well as their clinics, labs and research institutions, which exert pressure for and reward such claims.

Globally, there has been much discussion of the ethical and social implications of editing the genomes of our future children. Most reports suggest that the main potential use of genome editing would be therapeutic genome editing, to prevent the transmission of genetic diseases, such as cystic fibrosis (Nuffield Council on Bioethics, 2018). But in most cases, couples at risk of transmitting a genetic disease to their children can undergo PGT or prenatal diagnosis. 
The controversial use of genome editing is for genetic enhancements, where the couple want to have children with a characteristic that they do not carry, such as a particular eye colour.

The National Academies of Sciences, Engineering, and Medicine report concluded that first, peer-reviewed preclinical research is required to establish the risks and benefits, which should be followed by clinical trials only for compelling medical reasons in the absence of alternative treatments. It laid out a regulatory framework that included ten recommended criteria (National Academy of Science, 2018).

The Nuffield Council of Bioethics report stated that, before genome editing should be allowed, we need a broad societal debate to hear what the public thinks, then clear legislation on whether and to what degree the technology should be allowed, but we also need robust studies to ensure that the procedure is safe and efficient (Nuffield Council on Bioethics, 2018). The Nuffield report concluded that two overarching principles need to be considered: the welfare of the future person and that this technology should not increase disadvantage, discrimination or division in society.

UNESCO has issued a statement (UNESCO, 2018) to remind governments and the scientific community of the ethical principles of the Universal Declaration on the Human Genome and Human Rights (1997).

\section{Conclusions}

Fifteen years ago, the US President's Council on Bioethics held hearings on the question of Assisted Reproductive Technologies in the Genomics Era (Bioethics Archive, 2002), inviting testimony from NIH Director Francis Collins (Collins, 2002) and Gerald Schatten (Schatten, 2002). The scientific, medical, technical, bioethical, religious, social, legal and societal issues which were raised, then and before, continue.

In conclusion, any research in this area needs to be peer reviewed and published in the scientific literature, with all the necessary preliminary work, so that we can make a valued analysis of the technique. It is essential that research is undertaken to support the safety of human genome editing, but we also need to facilitate public debate. The transfer of these edited embryos is far too premature, and globally, we need to rapidly develop governance to control the future use of this technology, both for the benefit of society and for the sake of any future children born from edited embryos. Therefore, we are not ready for genome editing in human embryos FOR CLINICAL PURPOSES. 


\section{References}

Argyle, C, Davies, M and Harper, JC (2016) Oocyte cryopreservation: where are we now? Human Reproduction Update, 22(4):440-9

Barritt JA, Brenner CA, Malter HE, Cohen J. Mitochondria in human offspring derived from ooplasmic transplantation. Hum Reprod. 2001 Mar;16(3):513-6.

Blake L, Carone N, Raffanello E, Slutsky J, Ehrhardt AA, Golombok S. (2017) Gay fathers' motivations for and feelings about surrogacy as a path to parenthood.Hum Reprod. 2017 Apr 1;32(4):860-867. doi:

10.1093/humrep/dex026. PMID: 28333218

Bioethics archive (2002)

https://bioethicsarchive.georgetown.edu/pcbe/reports/beyondtherapy/chapter2.ht $\underline{\mathrm{ml}}$

Brenner CA1, Barritt JA, Willadsen S, Cohen J. Mitochondrial DNA heteroplasmy after human ooplasmic transplantation. Fertil Steril. 2000 Sep;74(3):573-8.

Chan AW1, Chong KY, Martinovich C, Simerly C, Schatten G. (2001) Transgenic monkeys produced by retroviral gene transfer into mature oocytes. Science. 2001 Jan 12;291(5502):309-12.

Collins, F., (2002) Genetic Enhancements: Current and Future Prospects, Presentation at the December 2002 meeting of the President's Council on Bioethics, Washington, D.C. Transcript available on the Council's website at www.bioethics.gov

Ethics Committee of the American Society for Reproductive Medicine, 2015, 2018

Flannigan R, Bach PV, Schlegel PN (2017) Microdissection testicular sperm extraction. Transl Androl Urol. 2017 Aug;6(4):745-752. doi: 10.21037/tau.2017.07.07.

Graham S. (2017) Being a 'good' parent: single women reflecting upon 'selfishness' and 'risk' when pursuing motherhood through sperm donation. Anthropol Med. 1-16. doi: 10.1080/13648470.2017.1326757.

Handyside AH Designer babies almost thirty years on. Reproduction. 2018 Jul;156(1):F75-F79. doi: 10.1530/REP-18-0157. Epub 2018 Jun 13. 
Handyside AH, Kontogianni EH, Hardy K, Winston RM. (1990) Pregnancies from biopsied human preimplantation embryos sexed by $\mathrm{Y}$-specific DNA amplification. Nature. 19;344(6268):768-70. PubMed PMID: 2330030.

Harper, J.C., and Handyside, A.H. (1994) The current status of preimplantation diagnosis. Current Obs and Gynae. 4, 143-149

Harper, JC (1996) Preimplantation diagnosis of inherited disease by embryo biopsy. An update of the world figures. J. Assit Reprod. Genet. 13(2)90-94

Harper JC. (2018) Preimplantation genetic screening. J Med Screen. Mar;25(1):1-5. doi: 10.1177/0969141317691797. Epub 2017 Jun 14. PMID: 28614992

Hui Yang, Yixue Li, Erwei Zuo, Yidi Sun, Wu Wei, Tanglong Yuan, Wenqin Ying, Lars M. Steinmetz Off target effects - Base editing generates substantial off-target single nucleotide variants doi: https://doi.org/10.1101/480145 -. https://www.biorxiv.org/content/early/2018/11/27/480145

Lander ES, Linton LM, Birren B, Nusbaum C, Zody MC, Baldwin J, Devon K, Dewar K, Doyle M, FitzHugh W et al. Initial sequencing and analysis of the human genome. Nature 2001;409:860-921.

Li XJ, Tu Z, Yang W, Li S. CRISPR: Established Editor of Human Embryos. Cell Stem Cell. 2017;21(3):295-296.

Liu Z, Lu Z, Yang G, Huang S, Li G, Feng S, Liu Y, Li J, Yu W, Zhang Y, Chen J, Sun $Q$, Huang $X$. Efficient generation of mouse models of human diseases via ABE- and BE-mediated base editing. Nat Commun. 2018, 14;9(1):2338.

Ma H, Marti-Gutierrez N, Park SW, Wu J, Hayama T, Darby H, Van Dyken C, Li Y, Koski A, Liang D, Suzuki K, Gu Y, Gong J, Xu X, Ahmed R, Lee Y, Kang E, Ji D, Park AR, Kim D, Kim ST, Heitner SB, Battaglia D, Krieg SA, Lee DM, Wu DH, Wolf DP, Amato P, Kaul S, Belmonte JCl, Kim JS, Mitalipov S. Correction of a pathogenic gene mutation in human embryos. Nature. 2018. 560(7717): E10E23.

Mehravar M, Shirazi A, Nazari M, Banan M. (2019) Mosaicism in CRISPR/Cas9mediated genome editing. Dev Biol;445(2):156-162. doi:

10.1016/j.ydbio.2018.10.008. Epub 2018 Oct 22.

National Academy of Sciences, 2017 Human Genome Editing. https://www.nap.edu/catalog/24623/human-genome-editing-science-ethics-andgovernance 
New York Times (2018) https://www.nytimes.com/2018/12/01/sundayreview/crispr-china-babies-gene-editing.html

New York Times (2019) https://www.nytimes.com/2019/01/21/world/asia/chinagene-editing-babies-he-jiankui.html."

Nobel Prize (2007) - https://www.nobelprize.org/prizes/medicine/2007/advancedinformation/

Nagy, A., Gertsenstein, M., Vintersten, K., Behringer, R. (2003) Manipulating the mouse embryo: A laboratory manual; 3rd Edition, Cold Spring Harbor Laboratory, New York.

Nuffield Council on Bioethics (2018) Genome Editing and Human Reproduction: Social and Ethical Issues,

Palermo GP, Pregnancies after intracytoplasmic injection of single spermatozoon into an oocyte. Lancet 1992:340:17-18.

Waddington, SN, Privolizzi, R, Karda, R and O'Neill HC (2016) A Broad

Overview and Review of CRISPR-Cas Technology and Stem Cells Curr Stem Cell Rep. 2016; 2(1): 9-20. doi: 10.1007/s40778-016-0037-5

Sauer MV (2015) Reproduction at an advanced maternal age and maternal health. Fertil Steril. 2015 May;103(5):1136-43. doi: 10.1016/j.fertnstert.2015.03.004.

Schatten, G, Prather R. and I. Wilmut I, Cloning Claim Is Science Fiction, Not Science, Science. 2003 Jan 17;299(5605):344.

Schatten G. Safeguarding ART. Nat Cell Biol. 2002 Oct;4:s19-22.

Schatten G, Hewitson L, Simerly C, Sutovsky P, Huszar G. Cell and molecular biological challenges of ICSI: ART before science? J Law Med Ethics. 1998 Spring;26(1):29-37, 3. PMID: 11067583

Edwards $\mathrm{R}$ and Steptoe $\mathrm{P}$, Birth after the reimplantation of a human embryo, The Lancet, Vol. 21978366

Jonathan Strecker, Sara Jones, Balwina Koopal, Jonathan Schmid-Burgk, Bernd Zetsche, Linyi Gao, Kira S. Makarova, Eugene V. Koonin \& Feng Zhang.

Engineering of CRISPR-Cas $12 \mathrm{~b}$ for human genome editing. Nature Communications, 10: 212 (2019).

Theobald R, SenGupta, S, Joski-Jethi C, Harper JC (submitted) The current status of preimplantation genetic testing in the UK and USA 
UNESCO (2018) https://en.unesco.org/news/unesco-cautions-against-recklessapplication-gene-editing

Universal Declaration on the Human Genome and Human Rights (1997). https://en.unesco.org/news/unesco-cautions-against-reckless-application-geneediting

Venter JC, Adams MD, Myers EW, Li PW, Mural RJ, Sutton GG, Smith HO, Yandell M, Evans CA, Holt RA et al. The sequence of the human genome. Science 2001; 291:1304-1351.

Wilson, C (2018), Exclusive: A new test can predict IVF embryos' risk of having a low IQ, New Scientist, https://www.newscientist.com/article/mg24032041-900-exclusive-anew-test-can-predict-ivf-embryos-risk-of-having-a-low-iq

Wilson LOW, O'Brien AR, Bauer DC. (2018) The Current State and Future of CRISPR-Cas9 gRNA Design Tools. Front Pharmacol. 2018 Jul 12; 9:749. doi: 10.3389/fphar.2018.00749. eCollection

Xinhua (2019) http://www.xinhuanet.com/local/2019-01/21/c 1124020517.htm

Zhang, F, Wen, Y and Guo, X (2014) CRISPR/Cas9 for genome editing: progress, implications and challenges. Human Molecular Genetics, Volume 23, Issue R1, R40-R46,https://doi.org/10.1093/hmg/ddu125

Zhang J, Liu H, Luo S, Lu Z, Chávez-Badiola A, Liu Z, Yang M, Merhi Z, Silber SJ, Munné S, Konstantinidis M, Wells D, Tang JJ, Huang T. Live birth derived from oocyte spindle transfer to prevent mitochondrial disease. Reprod Biomed Online. 2017 Apr;34(4):361-368. doi: 10.1016/j.rbmo.2017.01.013. 